\title{
Jünger en la Gran Guerra. Reseña de la novela Tempestades de acero
}

Andrés Botero-Bernal

Universidad Industrial de Santander, Colombia 


\section{Jünger en la Gran Guerra. Reseña de la novela Tempestades de acero*}

\section{Jünger in the Great War. Review of the novel Storm of Steel}

Forma de citar (APA): Botero-Bernal, A. (2019). Jünger en la Gran Guerra. Reseña de la novela Tempestades de acero. Revista Filosofía UIS, 18(2), doi: 10.18273/ revfil.v18n2-2019013

Forma de citar (Harvard): Botero-Bernal, A. (2019). Jünger en la Gran Guerra. Reseña de la novela Tempestades de acero. Revista Filosofía UIS, 18(2), 261-271.

Fecha de recepción: 26 de marzo de 2019

Fecha de aceptación: 24 de abril de 2019

Andrés Botero Bernal: colombiano. Profesor titular de la Escuela de Filosofía de la Universidad Industrial de Santander.

Correo electrónico: botero39@gmail.com

ORCID: 0000-0002-2609-0265

Scopus ID: 55604950500 


\section{Jünger en la Gran Guerra. Reseña de la novela Tempestades de acero}

Leí Tempestades de acero, obra escrita por Ernst Jünger (2013), la cual tiene muchos méritos en la historia de la literatura. En primer lugar, es tanto un hito en la novela autobiográfica como en la novela bélica, pues armoniza muy bien la narración literaria, la descripción informativa propia del diario y la biografía más rigorista. En segundo lugar, porque si no fue la primera, habrá sido la segunda obra literaria alemana de envergadura que apareció sobre la Gran Guerra (19141918) ${ }^{1}$, con la adición de que fue este escrito el que sobrevivió al tiempo, junto con un puñado selecto de textos en lengua germana (como El caso del sargento Grischa (1927) de Zweig, Historia y desventuras del desconocido soldado Schlump (1928) de Grimm y Sin novedad en el frente (1929) de Remarque ${ }^{2}$ ), logrando ser considerada como una de las mejores obras de dicho conflicto hechas en el período de Entreguerras. En tercer lugar, porque la escribió, a diferencia de otras obras similares, alguien que vivió en las trincheras los cuatro años que duró esa contienda mundial. Recordemos que Jünger fue uno de los oficiales alemanes más condecorados en la historia del siglo XX. Obtuvo todas las condecoraciones militares alemanas posibles de la época, incluyendo la más preciada de todas: "Pour le Mérite", con tan solo 23 años; además, fue herido 14 veces, heridas que le dejaron cerca de 20 cicatrices, según informa el mismo autor en esta novela

\footnotetext{
${ }^{1}$ Hay que aclarar que, en cada uno de los países en contienda, incluyendo Alemania, aparecieron diarios de guerra (algunos más o menos novelados), cuentos y poemas, entre otros, escritos desde las trincheras, textos publicados incluso antes de que la Gran Guerra terminase. El caso más emblemático fue el diario de guerra del artillero francés Paul Lintier (muerto durante el conflicto), denominado Ma pièce, publicado en 1916 y que mereció todo tipo de elogios por parte de la Académie française y que fue traducido a otras lenguas, como el inglés y el español (ambas versiones en 1917). Dicho diario de Lintier, al que se le suma otra obra suya no menos importante, Le tube 1233, fue todo un éxito editorial y político en dichos años. Habría que añadir que fue relativamente común que circulasen cuentos, ensayos y poemas, con fines claramente propagandísticos, escritos por los literatos de la época, quienes creían que así cumplían con un deber patriótico. Al respecto, y a manera de ejemplo, véase la compilación de cuentos en lengua inglesa escritos durante la guerra y en los años inmediatamente siguientes a su terminación (López, 2008). Entonces, si bien abundó literatura al respecto, no la analizo aquí por varios motivos: primero, porque la mayor parte de dichos escritos (con notables excepciones, claro está) tuvieron más valor político que literario; segundo, porque muchos de dichos textos no lograron sobrevivir al tiempo; y tercero, porque de hacerlo desviaría la atención del lector.

${ }^{2}$ Valga señalar que Remarque, también veterano de guerra, fue un atento y agradecido lector de Jünger, influyendo en su notable novela antibélica de 1929 (Kiesel en Jünger, 2014a, p. 614).
} 
(Jünger, 2013, p. 306) como en su propio Diario (Jünger, 2014a, p. 631). Y todo eso siendo un oficial de baja graduación (alférez y, al finalizar la Gran Guerra, teniente) del arma de infantería (la mayoría de los condecorados con la medalla "Pour le Mérite" fueron oficiales de alta graduación y pilotos — ases— de guerra ${ }^{3}$.

Es raro, muy raro, encontrar un personaje de esta envergadura: un héroe de guerra, un oficial aclamado por su tropa, un gran literato, un estupendo ensayista y un reconocido científico natural $\left(\right.$ entomólogo ${ }^{4}$ ). Esta capacidad para brillar en varios frentes le valió una gran reputación a la vez que explica cierta soberbia y petulancia que le adjudicaban muchos de los que le conocían. Y fue esta fama la que le permitió a Jünger enfrentarse al nacionalsocialismo, de un lado, y al comunismo, del otro, sin tener que abandonar Alemania por sus convicciones políticas. Sí que hay historias para contar sobre los múltiples desplantes de Jünger al nazismo, en la década de los años treinta, así como de su vida bohemia cuando sirvió en París durante la Segunda Guerra Mundial. Sin embargo, nos centraremos en su obra de la Gran Guerra... pero que no pierda de vista el lector que estamos ante toda una leyenda viva (una especie de héroe trágico) de su momento (Fontaine, 1995).

Volviendo al texto que reseño, es importante señalar que este libro es la versión literaria de buena parte del Diario de Guerra (Jünger, 2014a), Diario que escribió durante las pausas de combate en sus cuatro años de servicio en el frente occidental alemán (casi siempre combatiendo contra los ingleses). Quien tenga la fortuna de leer su Diario verá que se repiten historias; eso sí, mejor contadas en Tempestades de acero. Agregamos que estas dos obras están emparentadas con El Teniente Sturm (Jünger, 2014b) publicada inicialmente en 1923, ya que esta última narra, igualmente, una porción de las anécdotas bélicas consignadas en el Diario y en Tempestades. Podría decirse que, desde la perspectiva literaria, es mucho mejor Tempestades, aunque la profundidad de las reflexiones que se encuentran en El Teniente — reflexiones que pueden servir como argumentos antibelicistases meritoria. Sintetizando, esta novela de 1923 presenta las pericias del Teniente Sturm (quien sería el propio Jünger), quien durante las pocas horas de descanso

\footnotetext{
3 "La Orden Pour le Mérite había sido instituida por el rey Federico Il y era la más alta condecoración militar prusiana. En la primera guerra mundial fue concedida 685 veces. Unas 480 cruces fueron a parar a generales, unas 70 a pilotos de caza, cuyos derribos de aviones enemigos eran bien visibles y se contabilizaban con exactitud, y sólo once a jefes de compañía de la infantería, cuyos méritos pasaban inadvertidos con demasiada facilidad, dado lo complejo y poco visible del campo de batalla (...) Jünger fue uno de los últimos soldados de la primera guerra mundial que la recibieron. En la segunda guerra mundial no se renovó esa condecoración; entre los caballeros influyentes de la orden, especialmente también en Jünger, era demasiado grande la aversión por la manera nacionalsocialista de hacer la guerra. Desde 1984 hasta su muerte fue Jünger el último titular vivo de la condecoración militar Pour le Mérite" (dice Kiesel en Jünger, 2014a, p. 649).

${ }^{4}$ Existe, por ejemplo, el Premio Ernst Jünger de entomología, instituido desde 1985 por el Land (Estado federado alemán) Baden-Württemberg, sumado a que hay varios coleópteros a los que se les dio el nombre de Jünger en homenaje al autor que ahora reseño (Kiesel en Jünger, 2013, p. 457).
} 
entre sus tareas militares consolida un club de conversación con dos oficiales amigos, de un lado, y escribe una novela (una novela dentro de la novela, de la que apenas se esbozan las primeras páginas), del otro. En este texto, El Teniente Sturm, se plantea la dualidad dramática de un militar que se debate entre la acción pura (de la guerra) y la contemplación (filosófica y estética), a la vez que destaca por sus reflexiones sobre el conflicto armado (que un lector puede tomar, aunque sin ser el propósito explícito del autor, como antibélicas). Lo anterior, porque Jünger pone el dedo en la llaga de los vacíos del discurso nacionalista y de cómo el Estado se ha vuelto una macroorganización donde los individuos solo son carne de cañón de un proceso de industrialización y estatalización de la guerra, nunca antes visto. Por ejemplo:

Desde la invención de la moral y de la pólvora, el principio de la selección natural por la supremacía del más fuerte ha perdido cada vez más importancia para el individuo. Se puede seguir con todo detalle cómo esa importancia ha ido pasando más y más al organismo del Estado, que, cada vez con más desconsideración, limita las funciones del individuo a las de una célula especializada. Hoy hace tiempo que uno no goza de estima por lo que realmente vale sino sólo por lo que vale en relación con el Estado. Mediante esa supresión sistemática de toda una serie de valores, en sí muy considerables, se generan hombres que ya no tienen capacidad de vivir por sí solos... En cambio, si se hiere de gravedad al Estado moderno, queda amenazada la existencia de cada individuo, al menos de la parte cuya subsistencia no proviene directamente del suelo, o sea, la mayor, con mucho (Jünger, 2014b, pp. 16-17).

Ya aclarada la genealogía de la novela, Tempestades fue publicada por primera vez en 1920. Por su éxito, se editó muchas veces más en Entreguerras (hasta la llegada del nazismo que receló de la obra) y luego de la Segunda Guerra Mundial, y en cada nueva edición Jünger la revisaba haciéndole cambios profundos, no tanto en las historias sino en la forma de narrarlas (los expertos cuentan siete revisiones fuertes a esta obra, siendo la última la de 1978 para sus Obras selectas, que es la que se tomó para el libro que ahora reseño). En términos generales, la novela tiene un acento nacionalista (aunque no tanto como para catalogarlo como obra de propaganda) y algo romántico, aspecto que se observa en las descripciones de la naturaleza o el elogio a la purificación que hace la guerra, como se puede observar en la siguientes citas: "La Guerra que tantas cosas nos quita, es generosa en este aspecto; nos educa para una comunidad masculina y vuelve a situar en el lugar que les corresponde unos valores que estaban semiolvidados" (Jünger, 2013, p. 333). "Tal vez no haya ningún otro lugar en que se perciba mejor que aquí en la trinchera la manera en que el espíritu de una época se cae a pedazos" (Jünger, 2014b, p. 337). Lo anterior deja en claro el acento conservador del autor, pero no tan conservador como para compartir ideario con el fascismo y el nazismo. 
Tampoco su conservadurismo nacionalista lo lleva a denigrar de sus oponentes ni a menospreciar a los judíos, aunque en este último caso Jünger, en su Diario, les lanza reprimendas —injustificadas - porque supuestamente, según cierta propaganda malintencionada, los hebreos alemanes se negaban a combatir en las trincheras (Jünger, 2014a, p. 644). Ni siquiera vitupera a las tropas coloniales francesas e inglesas a las que se enfrentó en algunas oportunidades, a pesar de que era común en su momento una visión peyorativa de estos soldados ultramarinos. En Jünger podemos encontrar un respeto fuerte al soldado, amigo o enemigo, que igualmente delata el posterior rechazo que él tiene de las tesis xenófobas que pululaban en la Europa de Entreguerras. En este sentido, Ilama la atención la dedicatoria del libro "A los caídos", pero no solo a los alemanes, sino a todos. Al respecto, dice Jünger:

En la guerra he aspirado siempre a contemplar sin odio al adversario, a apreciarlo como hombre de acuerdo con su valor. Me he esforzado en buscarlo en la lucha para matarlo y no he esperado de él otra cosa. Pero nunca he pensado que fuera un ser vil (2013, p. 61).

Incluso, de vez en cuando, encontramos claros elogios al enemigo, casi siempre a soldados del Imperio Británico (Jünger se enfrentó a soldados de dicho Imperio que venían de todos los rincones del planeta), al considerarlos como personas viriles y audaces (2013, p. 132).

Ahora bien, tal como lo dijimos antes, la novela no puede clasificarse como antibélica, a pesar de que en ella no dejamos de encontrar críticas al conflicto, como las dirigidas hacia las malas decisiones del alto mando que conllevaron la muerte, sin sentido, de millares de jóvenes. Para dar un caso, Jünger (2013, p. 323) rechaza la orden de destruir las galerías subterráneas a las trincheras que salvaguardaban la vida de los soldados durante los bombardeos. Un antibelicista encontraría buenas citas en esta obra para su propio beneficio, pero no olvidemos que Jünger le da un valor partero a la guerra, cosa que mencionaremos más adelante.

Igualmente, en esta novela no podía faltar la típica escena de encuentro entre el soldado asesino y el enemigo recién asesinado, escena que se va a repetir hasta el cansancio en cuanta novela y película bélica se haga: cuando se le esculcan las pertenencias al enemigo recién muerto, para buscar mapas o armas, el soldado asesino encuentra sus cosas personales y con ellas la fotografía de su esposa o novia, y la de su familia, lo que produce un escozor fruto de la correspondiente empatía que esto produce entre guerreros curtidos pero que no por ello dejan de ser seres sintientes (Jünger, 2013, p. 247). Empatía que va más allá de las órdenes de no fraternizar dadas por el alto mando: "El Estado, que nos exime de la responsabilidad, no puede librarnos de la aflicción; éste es un asunto que hemos de dirimir nosotros mismos. La aflicción penetra hasta las profundidades de nuestros sueños" (Jünger, 2013, p. 256, idea que se repite en la 
p. 263). Sin embargo, "debemos desterrar, por tanto, toda aflicción, pues volverán a ser cultivados los campos, volverán a ser edificadas las aldeas y volverán a ser engendrados más seres humanos de los necesarios -pero el Tiempo y el Destino se acercan a nosotros de manera inapelable" (Jünger, 2013, p. 328).

Otro aspecto por resaltar es la detallada descripción tanto de las batallas, como del aburrimiento del soldado cuando el frente está largamente tranquilo (v. gr. Jünger, 2013, pp. 45-53). Así, la lucha no era solo contra el enemigo, sino también contra el tedio: "Lo que sobre todo no debe hacer el soldado es aburrirse" (Jünger, 2013, p. 94). Descripciones precisas que se acompañan de una excelente y amena narración. De allí que haya dicho antes que estamos ante un hito de dos géneros literarios: la novela bélica y la biografía. No es fácil encontrar un adecuado equilibrio entre el estilo ameno y el dato recio, asunto que queda patente en frases como esta (que también hablan de la buena traducción de la edición que reseño): "La soledad es absoluta; sólo la atanasia y la aquilea mecen sus umbelas por encima del borde de la trinchera y el llantén alza sobre los desiertos caminos sus diminutas mazas de armas" (Jünger, 2013, p. 342).

Por demás, es tal la descripción de la rutina del soldado y la explicación de estrategia, táctica y logística militar, que esta novela podría servir tanto de fuente primaria al historiador, como manual de servicio para futuros militares (en especial, si se piensa de nuevo, por más trágico que sea esto para la humanidad, en una guerra de trincheras). Al respecto puede mencionarse, a manera de ejemplo, la destreza y la precisión de la exposición de todos los servicios militares necesarios para mantener a una compañía en el frente (v.gr. Jünger 2013, pp. 124 y ss., y p. 420). También, las buenas lecciones que da sobre cómo tratar con soldados insubordinados (Jünger, 2013, pp. 393-394), lecciones que podrían sacar del lector palabras como estas: iqué astucia maquiavélica la de este joven alférez! ${ }^{5}$.

Otro caso de estas explicaciones de ciencia militar, se evidencia en la exposición que Jünger hace de las diferentes fases que tuvo dicho conflicto, afirmación que tiene igualmente un alto valor histórico:

Era la batalla del Somme, que proyectaba ya sus sombras. Con ella terminaría el primer período de la guerra, el más sencillo; entrábamos ahora, por así decirlo, en una nueva guerra. Aunque ciertamente nosotros no lo sospechábamos, lo que hasta aquel momento habíamos vivido había sido el intento de ganar la guerra por medio de batallas campales al viejo estilo, así como el fracaso de ese intento, que quedó varado en la guerra de posiciones. Ahora se alzaba ante nosotros la guerra de material, con su gigantesco despliegue de medios. Y a finales del año 1917 la guerra de material sería sustituida por la batalla mecánica, cuya imagen no llegó, sin embargo, a desarrollarse por completo (Jünger, 2013, p. 73, aspecto que luego desarrolla mejor en p. 277 y p. 349).

\footnotetext{
${ }^{5}$ Se trata de una carta que remite a su hermano, sobre cómo debería contrarrestar, por medio de la astucia, una revuelta de soldados camino al frente.
} 
Pero ni siquiera una "guerra de máquinas" puede reemplazar el valor del guerrero, pues "El combate no es ganado por la máquina, sino con la ayuda de la máquina -y ésta es una gran diferencia" (Jünger, 2014b, p. 349).

No obstante, a pesar del tono serio que impera en la obra, hay espacio para el humor, que se vislumbra en las escenas graciosas que describe, pues en la guerra hay momento y espacios para todo, en especial en ciertas descripciones, algo lacónicas pero que el lector puede leer entrelíneas, de las juergas y las borracheras de los soldados: "gastamos en vino hasta la última moneda que nos quedaba, pues ¿para qué necesitábamos ya el dinero? Al día siguiente estaríamos, o más allá de las líneas enemigas, o en un Más Allá todavía mejor" (Jünger, 2013, p. 235). En fin, "son pocas nuestras alegrías. En realidad sólo tenemos una: beber y divertirnos en compañía de los camaradas... La embriaguez es para nosotros una pregunta que hacemos a la Vida" (Jünger, 2013, p. 389).

Un ejemplo de ese humor negro está en la siguiente descripción de cierto tipo de parapeto para proteger las tropas: "Lo único que me tenía preocupado era su cubierta; lo más que de ella podía decirse era que su resistencia a las bombas era relativa, esto es, que resistiría con tal que encima de ella no cayese ningún proyectil" (Jünger, 2013, p. 275). O al momento de preguntar por qué un ataque con tantas municiones, bombas y morteros por parte del enemigo, cuando no le aparecía claro el objetivo de dicho ataque: "Sólo por divertirse no habrán lanzado a los aires la mitad de un empréstito de guerra" (Jünger, 2013, p. 415) ${ }^{6}$. En últimas, "existe una relación profunda entre el humor y el espanto" (Jünger, 2013, p. 413).

Otro aspecto que quiero resaltar es la amplia cultura general y gran dominio de la literatura universal y de la filosofía de aquel jovenzuelo quien, entre combates, leía lo que le cayera en las manos mientras escribía su Diario con una prosa inigualable. Sus obras literarias están Ilenas de citas y menciones a obras literarias de todo tipo, así como a analogías y metáforas que dan cuenta de una persona con una cultura excepcional, no sólo por la edad del autor sino en especial por la profundidad de todas ellas (las citas, las analogías y las metáforas). Resalto una de la obra que ahora reseño: "Hasta entonces el bosque no nos había dejado ver los árboles" (Jünger, 2013, p. 178); o esta otra para explicar el movimiento de protección que hace el soldado cuando explota un proyectil cerca de él: "Yo estaba arriba, en el borde, y, cada vez que explotaba una granada, veía cómo abajo los cascos de acero, iluminados por la luz de la luna, hacían una reverencia unánime y profunda" (Jünger, 2013, p. 211). O la forma en la que alude a los olores nauseabundos del campo de batalla, en especial por la mortecina: "perfume de ofensiva" (Jünger, 2013, p. 273). O esta otra, con cierto tinte crítico-político: "Tal vez mañana el comunicado oficial del ejército -el periódico más grande y

${ }^{6}$ Buena parte de los esfuerzos de guerra de todos los bandos del conflicto se hizo por medio de empréstitos forzosos que debían suscribir los ciudadanos. 
lacónico del mundo- [...]" (Jünger, 2013, pp. 315-316). O la descripción de la "esponja", como se denomina irónicamente a la guerra de documentos, propio de un ejército que no olvida a sus tramitadores y burócratas: "El número de los soldados combatientes disminuye día a día, mientras aumenta cada vez más el número de esa gente" (Jünger, 2013, p. 386). Y es que todo tiene un formato y un procedimiento administrativo que describe nuestro autor con profunda gracia: "El trato que damos a esos papeles se rige, pues, por la regla que dice que no existe ningún asunto urgente que no se vuelva más urgente todavía cuando se lo deja reposar" (Jünger, 2013, p. 385). En suma, una guerra que también se libra en "despachar una enorme cantidad de pequeñeces" (Jünger, 2013, pp. 417-418).

Entre las menciones que hace Jünger de la literatura universal, es menester enfatizar una obra que va a cumplir un importante rol en la creencia de la purificación que la guerra hace del soldado y del Hombre: el poema épico de Orlando furioso (1516) de Ariosto, texto que leyó de una sentada cuando estaba con su destacamento descansando del frente en mayo de 1917 (Jünger, 2013, p. 150), poema del que tomó una frase que repetía constantemente en momentos críticos: "A un corazón grande no le horroriza la muerte, llegue cuando llegue, con tal de que sea gloriosa" (Jünger, 2013, p. 181), de manera tal que de la guerra, creía Jünger, surgiría un hombre nuevo, pero no uno que niega el miedo, sino el que lo enfrenta con valor: "el hombre sin miedo no existe... si el miedo no existiera, carecería de sentido el valor" (Jünger, 2013, p. 310). "Este período tardío, y acaso último de la guerra se ha encarnado en la figura de un combatiente purificado por el fuego; esa figura será sin duda la que quedará fundida con la imagen de la Gran Guerra" (Jünger, 2013, p. 431). Renacimiento humanista, en el crisol de la guerra, que se deberá, entre otros factores, a la disciplina prusiana que funge de partera socrática: "Y si bien es cierto que al principio choqué violentamente con ella, con todas y cada una de sus normas, le debo más que a todos los maestros de escuela y a todos los libros del mundo" (Jünger, 2013, p. 448).

Otro aspecto es el homenaje que él hace a sus buenos superiores, por ejemplo, a su comandante de regimiento, Coronel von Oppen (Jünger, 2013, p. 234), así como a varios de sus compañeros y subalternos, a los que halaga con su nombre propio. Cobran importancia las páginas especiales que dedica a elogiar a sus ordenanzas (o asistentes, por llamarlos así), como Vinke, Schüddekopf e incluso al indolente pero valiente Otto, logrando conseguir para ellos el afecto del lector. En esta línea, rara vez el autor censura a un compañero de armas, pero al hacerlo, se cuida mucho de no dar mayores datos de él, ni dar sus nombres propios. A fin de cuentas, son camaradas de guerra.

Ya para finalizar, no puedo dejar de señalar mi impresión, como lector de las historias bélicas que protagonizó el alférez (y teniente) Jünger, que es el hombre más afortunado que haya pisado las trincheras en aquella guerra. Estamos ante 
el hombre al que mejor se le barajaron las "cartas del Destino" (Jünger, 2013, p. 142), cartas que, como escribe el propio oficial, suelen favorecer a dos tipos de soldados: el más precavido y el más indiferente, castigando a los que quedaban en medio de dichos extremos (Jünger, 2013, p. 143). Claro está que tantas heridas de combate resaltan que su fortuna no fue completa, pero muy pocos pudieron contar que estuvieron en las batallas más sangrientas y que salieron vivos (heridos, pero vivos). A lo que se suma que no fue una víctima de la "gripe española", que en 1918 fue más carnicera que las balas del enemigo (Jünger, 2013, p. 279) ${ }^{7}$.

Es que, como lo deja entrever el propio Jünger, las probabilidades de salir ileso de una de esas batallas en las que participó eran casi que cero (efectivamente en casi todas ellas, Jünger fue herido), pero salir vivo con heridas curables, eso sí que era una suerte tremenda. Y si algo queda claro de un relato también famoso de la época, Historia y desventuras del desconocido soldado Schlump (Grimm, 2014), las probabilidades de morir o de ser herido gravemente eran muchísimo más altas que las de salir con una herida curable (y ni hablar de salir indemne) de una batalla (Grimm, 2014, pp. 144-154). El soldado enajenado por la propaganda esperaba una oportunidad para destacar con una hazaña, pero esta casi nunca llegaba porque en la "guerra de material", muy pocas veces se tenía la oportunidad de combatir realmente contra el enemigo... lo que se hacía era estar aferrado a la tierra esperando que una esquirla de granada, una bala perdida o un explosivo sin rumbo, no enviase al soldado al cementerio (si es que había oportunidad de tal cosa) o al hospital (para morir probablemente entre moribundos adoloridos).

En este sentido es que decimos que Jünger fue un hombre con suerte, con muchísima suerte. Una que si no fuese por la confirmación oficial (que dio lugar a las condecoraciones recibidas) y la propia narración del protagonista en su Diario de guerra, parecería sacada de la ciencia ficción, de la literatura fantástica o de la mente pervertida de un mitómano. Son casi una docena de veces que al propio Jünger le cayeron encima morteros y granadas que no estallaron, balas que chocaban con un botón de su uniforme o con la hebilla de su correa, esquirlas que rozaron su casco de acero, etc. Tal vez, podría pensarse ligeramente, que tantas condecoraciones y fama de heroicidad no fueron tanto por las hazañas realizadas, que no fueron pocas, sino por la suerte de este hombre, una que despertaba coraje entre sus subalternos, alegría entre sus colegas, admiración e incredulidad entre sus superiores y orgullo en quien la gozó y la supo exponer en este libro que ahora presento.

\footnotetext{
${ }_{7}^{7}$ Se trató de una pandemia devastadora (hay quienes dicen que ha sido la peor pandemia de la humanidad de la que se tiene noticia registrada). En un solo año, 1918, mató entre 40 y 100 millones de personas, especialmente entre las tropas de todos los bandos, por las malas condiciones de salubridad en las que se encontraban.
} 


\section{Referencias}

Fontaine, A. (1995). ¿Por qué Jünger? Estudios Públicos, 58, 423-436.

Grimm, H. (2014). Historia y desventuras del desconocido soldado Schlump. (B. Santana, trad.). Salamanca: Impedimenta.

Jünger, E. (2013). Tempestades de acero. (A. Sánchez Pascual, trad.). Buenos Aires: Tusquets.

Jünger, E. (2014a). Diario de guerra (1914-1918). Edición a cargo de Helmuth Kiesel. (C. Gauger, trad.). Buenos Aires: Tusquets.

Jünger, E. (2014b). El teniente Sturm. (C. Gauger, trad.). Buenos Aires: Tusquets.

López, J. (2008). (Ed.). Cuentos de la Gran Guerra. (J. López, trad.). Barcelona: Alpha Decay. 